\title{
First exposure to Arduino through peer-coaching: impact on students' attitudes towards programming
}

Pablo Martín-Ramos ${ }^{1 *}$, Maria João Lopes ${ }^{2}$, M. Margarida Lima da Silva², Pedro E. B. Gomes $^{2}$, Pedro S. Pereira da Silva ${ }^{3}$, José P. P. Domingues ${ }^{4}$ and Manuela Ramos Silva ${ }^{3 *}$

${ }^{1}$ EPSH, Universidad de Zaragoza, Carretera de Cuarte s/n 22071 Huesca, Spain. Phone: +34 (974) 292668; Fax: +34 (974) 239302; E-mail: pmr@unizar.es.

2 jeKnowledge, Universidade de Coimbra, Rua Larga P-3004-516 Coimbra, Portugal.

${ }^{3}$ CFisUC, Department of Physics, Universidade de Coimbra, Rua Larga P-3004-516 Coimbra, Portugal. Phone: +351239410648; Fax:+351239829158; E-mail: manuela@pollux.fis.uc.pt.

${ }^{4}$ Biomedical Institute for Research on Light and Image, IBILI, Universidade de Coimbra, Azinhaga Santa Comba, Celas 3000-548 Coimbra. 


\title{
First exposure to Arduino through peer-coaching: impact on students' attitudes towards programming
}

\begin{abstract}
In this paper we report the work that jeKnowledge (Júnior Empresa da Faculdade de Ciências e Tecnologias da Universidade de Coimbra), a student-led initiative, has done in the 'jeKnowledge academy' courses to actively engage Portuguese high-school students in STEM education through hands-on projects based on the low-cost Arduino platform. F2F activities, based on a peer-assisted learning strategy, were complemented with tutorials and more advanced project suggestions in a blog. Pre and post surveys on students' attitudes towards programming and peer-coaching were administered to pre-university and first year college participants, finding an overall increase in the Likert scale for all the programming-related constructs under study (confidence, interest, gender, usefulness and professional) after the introductory course. As regards the peer-based learning approach, younger students seemed to be more eager to be taught in a less formal way than their older counterparts. The course resulted in high degrees of satisfaction for both the student tutors and their tutees.
\end{abstract}

Keywords: Attitudes survey; Arduino; High School; programming; peer coaching.

\section{Introduction}

This paper reports details on an introductory Arduino course and the results of surveys administered to pre-university and first year students attending a school of science and engineering. It constitutes a first effort to understand Portuguese students' attitudes towards programming and to gain insight on what encourages/discourages them from pursuing degrees in computer science and related disciplines, in addition to evaluating their postures and beliefs about peer-based learning.

Building on the work developed by Hoegh and Moskal (2009) on validated assessment instruments to support the measurement of students' attitudinal changes as a result of interventions in computer science and information technology, a survey that could measure five constructs (confidence in their ability to learn computing skills, interest in computing, gender bias in the field, usefulness of learning computing and professional prospects) was administered to tutees. The survey was further expanded to include their views on the chosen peer assisted learning strategy (PALS).

Out of the five constructs, the gender related one is, in our view, particularly relevant: the lack of gender diversity in the computing field is problematic not only in terms of equity, but also for innovation, as noted by several entities (e.g., the National Center for Women \& Information Technology (NCWIT), the Association of Computing Machinery (ACM-W), and the Anita Borg Institute (ABI)). In particular, they place emphasis on the need for women to be a much greater part of the equation as the field moved into its next phase (DuBow, Quinn, Townsend, Robinson, \& Barr, 2016). Stereotypical attitudes towards women in computer-related activities go beyond the professional sphere, affecting even leisure activities such as gaming (Kaye \& Pennington, 2016). Consequently, it is important for tutees to have female role-models as tutors, which is actually a common practice in jeKnowledge.

jeKnowledge (Júnior Empresa da Faculdade de Ciências e Tecnologias da Universidade de Coimbra, http://jeknowledge.pt/) is a student-led initiative that started in 2008, aimed at offering students from the Science and Technology School at the University of Coimbra (Portugal) the possibility of applying the knowledge acquired in their higher education degrees to the global market, through different internal and external projects. This initiative not only works as a start-up incubator, but also organizes summer schools for 14 to 17 year-old high-school students and courses 
for freshmen in STEM degrees at Universidade de Coimbra. These courses (jeKnowledge academy) are primarily aimed at actively engaging 14 to 17 year-old high-school students in Science, Technology, Engineering and Mathematics (STEM) learning through hands-on projects, but also introductory courses on programming (e.g., HTML, Arduino, Docker, ReactJS, RoR, etc.) are also taught to college students. In all cases, prior knowledge of programming is not a pre-requisite, only the desire to learn.

In order to expose the students to tools that will lead them to ideation, innovation, energy awareness and problem solving skills, which will enable them to become part of a very competitive workforce in the future, the ubiquitous embedded systems are an optimum platform (Benitti, 2012; Duncan \& Bell, 2015; Merkouris \& Chorianopoulos, 2015). Steve Jobs once said, "Everybody in this country should learn how to program a computer, because it teaches how to think". Many studies in programming, both in K-12 and higher education have reported the positive outcomes of this exposure to constructionism-based problem-solving learning environment, with authentic problem, information processing, scaffolding and reflection activities (Lye \& Koh, 2014). Going one step forward, the European Union is currently funding projects, such as TACCLE3, aimed at sharing experiences and resources to introduce computational thinking in the educational agenda of its member states in an optimized and coordinated manner (García-Peñalvo, 2016; Rees, García-Peñalvo, Jormanainen, Tuul, \& Reimann, 2016).

To teach a basic microcontroller is a challenging task, mostly at early stages (pre-university education). Some students may come with experience already on one or more particular microcontroller development platforms that they have used as hobbyists. On the other hand, the majority of students have not been exposed to any microcontroller platform at all. Moreover, there is a large number of alternatives available: CISC and RISC architectures; platforms that can be programmed very efficiently in assembly language and others using very high level languages; platforms that do not have any open source libraries to perform input/output interfaces and other ones that have a complete set of libraries; and platforms that hide all the microcontroller architecture and just focus on applications (Mondragon \& Becker-Gomez, 2012).

The chosen platform should satisfy five basic criteria: $(i)$ ease to program in assembly language and high level languages; (ii) ease to perform graphical system programming and configuration; (iii) possibility for students to apply it in project based learning (PBL); (iv) affordable for students to buy and experiment with; and $(v)$ useable later in their degree program. Consequently, in this case of study, we opted for the open source Arduino prototyping platform, that has all of the above traits and that had been successfully used for other similar experiences. For instance, Junior, et al. (2013) tested a low-cost educational robotics kit based on Arduino Uno platform with Secondary Education students, using a step-by-step approach and a block-structured environment, reporting substantial advantages over other alternatives based on standard and proprietary components. Assaf (2014) was also successful in introducing BotSpeak, a universal programming language for robotics, to K-12 students, selecting Arduino as one of the three preferred platforms (together with Raspberry Pi and LEGO Mindstorms). Arduino has been used in combination with Squeak e-toys to teach the object-oriented paradigm to middle school students, confirming positive results in both the cognitive domain and the definitional domain (Jang, Lee, \& Kim, 2015). RoboParty, a three-day camp organized at Universidade do Minho in Guimarães (Portugal), chose a teambased approach to teach electronics, mechanical engineering and programming to school age children, while they participated in various cultural and sports activities. Once again, the Bot'n Roll One A robotics kit used was an Arduino based one, and an increased interest in engineering resulted amongst the participants (Eguchi, 2014). The same change in high school students' perceptions of computing was also achieved by using Arduino-based e-textiles and scaffolded challenges by Kafai, et al. (2014); Kafai, et al. (2013). They observed that creative freedom helped students feel a great deal of ownership in designing their projects.

At a university level, Rubio, Hierro, and Pablo (2013) showed improved results when Arduino was used in introductory programming courses for undergraduate students as compared to traditional classes. Likewise, Aldridge, Brandt, and Parikh (2016), by using a PBL strategy with an Arduino Uno board, had their undergraduate students experience the entire design process 
when building the autonomous educational robots by themselves. They concluded that this platform was the most suitable when there were budget constraints, and observed a remarkable success. With this being said, using Arduino in an introductory microcontroller-based programing course is not a novel idea anymore, but innovation in the present work comes from the chosen peer assisted learning strategy.

Arduino can provide an introduction to microcontrollers without dwelling much into the programming aspect of it or the architecture aspect of it. The implementation of Processing used in Arduino IDE would be a $\mathrm{C} / \mathrm{C}++$ 'dialect', which make the transition easy for those who have just started learning $\mathrm{C}$ or any other language, and many graphical languages have been built around Arduino (e.g., Visuino, Ardublock, mBlock, miniblock, Snap4Arduino or Embrio, to name a few) that make it accessible even to non-programmers (Reas \& Fry, 2014). At the same time, this inexpensive microcontroller might create enough curiosity as to what this beautiful thing is capable of. Moreover, adding peripherals is not difficult, as many modules are available which can be simply attached to the Arduino board like fitting two Lego blocks together. With a huge amount of online tutorials and a large user base to ask questions, it can become a great start for creating interactive objects or environments.

Thus, this student-led teaching/learning initiative, based on short and informal courses, and the chosen platform, particularly suited for developing the cognitive skills and problem solving processes included in computational thinking (Barr \& Stephenson, 2011; Grover \& Pea, 2013; Lessner, 2014), were regarded as an opportunity to evaluate students' attitudes towards computer science and related disciplines and student to student-based learning.

\section{Materials and methods}

\subsection{Peer-coaching strategy}

A peer-coaching approach was chosen since it has been shown through various studies that it has a number of benefits for both tutors and tutees: for the former, it results in the improvement on a range of soft skills, such as presentation and communication skills, and even in selfconfidence (Smith, May, \& Burke, 2007); while for the latter it enhances their academic performance and thinking skills, and influences their ability to apply abstract ideas (Capstick \& Fleming, 2001; Emurian, Holden, \& Abarbanel, 2008; Lundeberg \& Moch, 1995; SerranoCámara, Paredes-Velasco, Alcover, \& Velazquez-Iturbide, 2014; Smith, et al., 2007).

\subsection{Courses organization}

The 8-hour voluntary seminars (similar for pre-university and the freshmen students) were split into two sessions, on two separate days, plus extra sessions in which the students showed the projects they had made in groups of 3-4 members. The seminars were taught by $2^{\text {nd }}$ to $4^{\text {th }}$-year students, both males and females, from the Physics Engineering/Design and Multimedia/Electrical Engineering degrees taught at Universidade de Coimbra.

The course consisted of a short introductory theoretical part, in which the students were taught the basics of Arduino and its programming language, and a hands-on section, in which 6 miniprojects were first covered by all the students, followed by extra time (on top of the 8 hours) to work on another project of their choice (in the case of older students). In this 'soft' PBL strategy, computational thinking skills are taught indirectly, since they are embedded in the programming concepts, similarly to the study by Duncan and Bell (2015).

\subsubsection{Theoretical introductory section}

The students were introduced to the open-source hardware philosophy, and general aspects about Arduino's make of, models and characteristics were discussed.

The fundamentals of Arduino programming language were then explained, covering only those variables, functions and structures that were needed to understand the code of the mini- 
project examples (Banzi \& Shiloh; McRoberts, 2010; Nussey, 2013). The aspects that could be more overwhelming (viz., memory mapping, peripheral interfacing, using timers and counters, serial and parallel communications, opcodes and operands, polling and interrupts, etc.) were safely skipped.

\subsubsection{Equipment}

Since the budget was somewhat limited, Arduino-compatible systems and only some components (USB cable, electrical wires, LEDs, resistors, capacitors, potentiometers, photoresistors, switches and a 7-segment display) were supplied, without providing an entire kit. Nonetheless, kits -such as Official Arduino Starter Kit, Funduino Advanced Starter Kit, Vilros Ultimate Starter Kit, Sunfounder Super Kit, DFRobot Beginner Kit for Arduino v3 or the ARDX Starter kit for Arduino, to name a few- which include all of the basics (an Arduino-compatible board, a breadboard, cables, LEDs, resistors and pushbutton switches) and other things that may help the student build some really fun things (temperature, flame, and infrared sensors; lightdependent resistors; a stepper motor; two sizes of seven-segment display; an LCD display; and even a joystick) would also be a desirable option.

It may also be worth opting for other Arduino-compatible devices that actually "add value" in comparison to the official board because of their additional features (e.g., the ESP8266 or 'NodeMCU' has built-in Wi-Fi for less than $\$ 10$, the LilyPad is designed for wearables and etextiles, etc.)

Arduino integrated development environment (IDE) open-source software, which runs on Windows, Mac OS X and Linux, was used to program the board.

\subsubsection{Practical section}

To keep students engaged in a course full of new concepts that could become overwhelming and that share very limited scope with what they use in their normal lives is a difficult task. Moreover, the current generation of students likes to receive immediate feedback, and in the case of a microcontroller course, they appreciate something that blinks or moves in response to their efforts.

A robotic platform can be very engaging, but limited in the applications they can develop early in their programs. In the chosen Arduino mini-projects, the students could familiarize themselves with the Arduino board and software by means of easy and rewarding examples.

Prior to starting with the mini-projects, the students were guided through the installation of Arduino software (IDE) in their laptops (students were encouraged to bring their own mobile devices to the classroom, to promote m-learning, in line with the findings of Castillo-Manzano, Castro-Nuño, López-Valpuesta, Sanz-Díaz, and Yñiguez (2017) and Chou, Chang, and Lin (2017)) and helped with the installation of the board drivers when necessary (Figure 1). A brief explanation of the toolbar buttons was provided, but the students managed to pick up the important concepts and how to use the IDE properly as they worked their way through the miniprojects. 


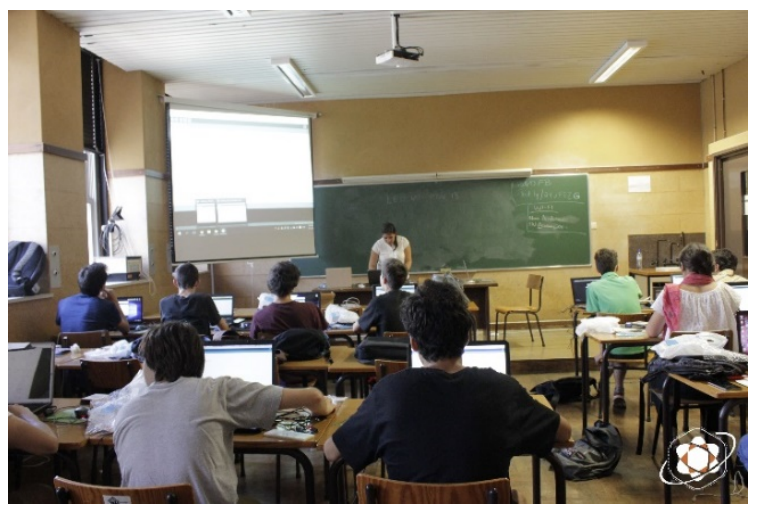

Figure 1. Guided installation of Arduino IDE, conducted by one of the female tutors.

Mini-project \#1: LED flasher. A 'must' in any Arduino course, this example (Arduino, 2015b) showed the students the simplest thing you can do with an Arduino to see physical output: it blinks an LED, turning it on and off for definite periods of time. This allowed them to learn the use of digitalWrite () and delay() commands (Figure 2).

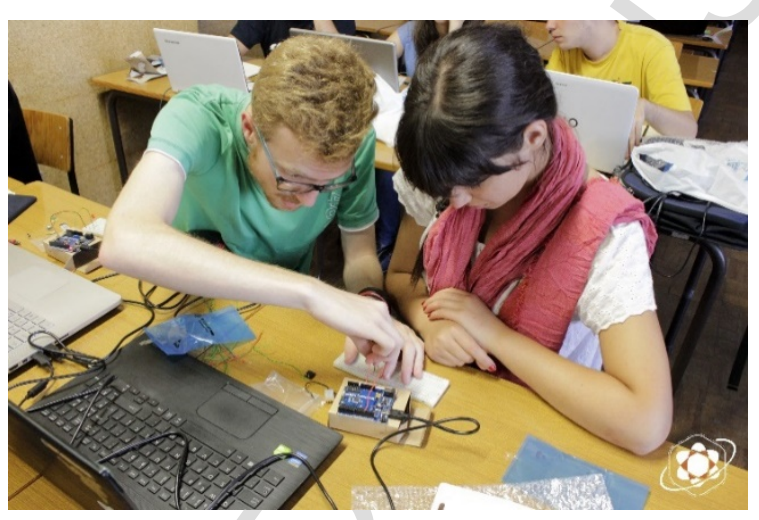

Figure 2. Peer coaching during the class (mini-project \#1).

Mini-project \#2: RGB LED. Supplied with the kit is an RGB LED, which has a red LED, a green LED and a blue LED (hence RGB) in one package. The students are shown how to create different colors by cross-fading, i.e., adjusting the brightness values, the R, G and B channels (adafruit, 2015). This also permits to comment on the additive color model. Students are encouraged to try adding colors of their own to the sketch and watching the effect on their LEDs.

Mini-project \#3: Dimming a LED. Here the students learn how to read an analog input pin (from the potentiometer), map the result to a range from 0 to 255, use that result to set the pulse width modulation (PWM) of an output pin to dim or brighten a LED and print the values on the serial monitor of the Arduino IDE (Arduino, 2015a).

Mini-project \#4: Turning on/off a LED with a LDR. By using photoresistor, also called lightdependent resistor (LDR), a light- and dark-activated switching circuit can be easily built. When it is dark, the resistance of a photoresistor may be as high as a few $\mathrm{M} \Omega$. When it is light, however, the resistance of a photoresistor may be as low as a few hundred ohms. In this experiment, we will connect a LDR to an Arduino analog input and read the value, and by using conditional statements, the Arduino will decide whether to turn the LEDs on or off (AllAboutCircuits, 2015). This trains the students in the most basic control structures, whose execution results in a choice being made as to which of two or more paths should be followed. This is in line with programmatic thinking skills such as approaching problems using iteration, symbolic representation, and logical operations techniques (Barr \& Stephenson, 2011; Grover \& Pea, 2013; Lessner, 2014). 
Mini-project \#5: Button-controlled LED. So as to learn the use of digitalRead (), the Arduino is used to turn on a LED when the student presses a button (Arduino, 2015c). The student is requested to modify the code in different ways: so that the LED will only be on while the button is pressed, so that it will remain on permanently at the button release, or so as to turn it off when the button is pressed again. This will also reinforce the understanding of the control structures learnt in previous mini-project.

Mini-project \#6: 7-segment display. This project uses the Arduino and a 7-segment display to show, for example, a countdown (Hacktronics, 2014). Since there is a lot of code which would be repeated and that could be minimized by using functions, the concept of function is introduced. This should promote one of the key problem-solving processes in computational thinking: breaking the problem down into smaller parts (Grover \& Pea, 2013).

Project \#7: 7-segment display-based expanded project. Older students were asked to complete a project in two weeks, in a group of 3-4 students, based on a digital LED display (Figure 3), so that numbers and letters typed in computer keyboard would appear on the display. Students could add any extra features to their final project (e.g., different lights blinking to distinguish numbers and letters, sound effects, a Morse code signaler, communication between several Arduino boards using Inter-Integrated Circuit (I2C) protocol, etc.). Project development for this final project was not supervised by the teacher/student. The projects were all presented in classroom and graded by the teacher. This final project aims to promote the students' ability to generalize and transfer the problem solving process to a wide variety of problems, to use abstractions and pattern recognition to represent problems in new and different ways, and to reformulate problems so that they can be solved using a series of ordered steps (algorithmic thinking) (Grover \& Pea, 2013).

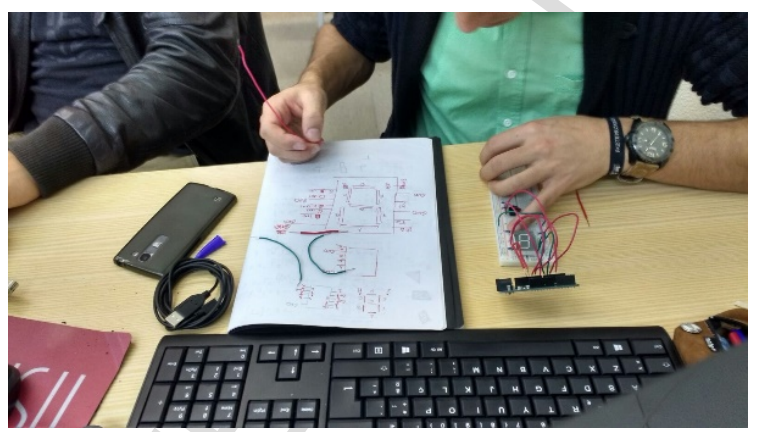

Figure 3. Student sketching a final free-choice project based on the 7-segment display

\subsubsection{After the course: online follow-up}

Upon completion of the course, a follow-up was conducted through a blog (jeKnowledge, 2016) (see Figure 4), in which new tutorials were posted: a virtual dice, a LED interface with Processing and Arduino, a memory game, a rain gauge, etc., encouraging the students that had taken part in the Courses to contribute with their comments and offering the younger students to work on a final project too (albeit in a non-supervised manner). Some of the original Arduino Starter Kit examples, now explained in Youtube (Arduino, 2014) by Massimo Banzi, such as a light Theremin, a crystal ball or a Twitter controlled mood lamp); or other cool projects from different web sources and books (Arduino, 2016a, 2016b; Craft, 2013; Faludi, 2010; Instructables, 2016; Javed; MakeUseOf, 2015; Monk, 2010) can also be used at this stage to promote their interest. However, this part has not meaning in the tests as they were performed before the students started this phase. 


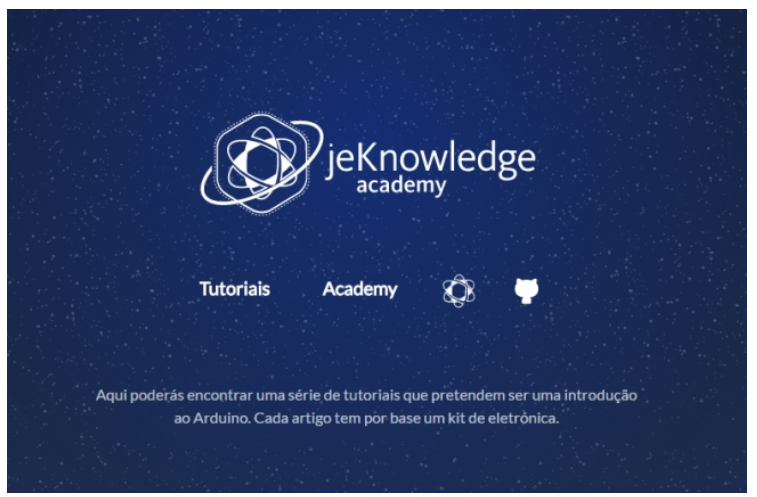

Figure 4. Screenshot of the blog's main page.

\subsection{Surveys}

\subsubsection{Survey participants}

Data was collected during 2016-2017 academic year in an 11 th year class (16-17 year-old students) from Escola Secundária Infanta Dona Maria (Coimbra, Portugal) and within a freshman level course, entitled "Physics Engineering Seminars", at the FCTUC, Universidade de Coimbra (Coimbra, Portugal). High school participants were selected as the target population for this investigation because this is a period in which students form opinions about future majors and careers, while the first-year university students were chosen because they are enrolled in a School of Science and Engineering but who are not currently pursuing a degree in computer science or information technologies. Therefore, the students in both educational levels should be representative across their respective institutions.

\subsubsection{Instrument}

The survey used was a faithful translation into Portuguese of that developed by Hoegh and Moskal (2009). The survey was originally designed to measure students' beliefs and attitudes towards computing with respect to five constructs. These five constructs were selected based on the qualitative research in computing concerning factors that discourage student enrollment in courses related to computer science: Confidence construct (C): students' confidence in their own ability to learn computing skills; Interest construct (I): students' interests in computing; Gender construct $(\mathrm{G})$ : students' perceptions of computing as a male field; Usefulness construct (U): students' beliefs in the usefulness of learning computing; and Professional construct (P): students' beliefs about professionals in computing.

In a similar fashion to the study reported by Heersink and Moskal (2010), the term "computer science" was replaced with "programming" in the survey presented herein. The pre survey was further expanded to include a new set of 5 questions on peer-coaching (PC), plus two demographic questions (asking for age and gender). The post survey also included two questions regarding whether the participants would recommend the course to a friend or not, and whether the course should be repeated on the following year with new freshmen or not, plus a space for short comments so that they could share their impressions in whether their views on programming and peer-coaching had changed after the course or not.

As in the original survey, questions were designed using a four point Likert scale with students responding to each question by choosing from "strongly disagree", "disagree", "agree", and "strongly agree" options. So as to encourage participants to make a positive/negative decision, a neutral category was not included.

The survey was administered to each of the participating groups through Google Forms, in a pre format in the case of the High School students (available at https://goo.gl/JJHkBF) and in a post format for the University ones (available at https://goo.gl/dJ1d5F). The pretest aims to measure students' attitudes with respect to programming without intervention, while the post one 
aims to assess the impact of the first exposure to programming (using the Arduino platform) through a peer assisted learning strategy. Questions were administered in random order and it was not compulsory to answer all questions.

\subsubsection{Survey data analysis}

For analysis purposes, the responses were re-coded to a numerical scale, ranging from 1 to 4 . So that a high score always reflected a positive attitude, negatively phrased questions had to be reversed coded. Likewise, a higher numerical score was associated to a gender neutral attitude in the gender construct questions. Since a new PALS construct was added to the survey (modifying the test that had previously being validated by Hoegh and Moskal), Cronbach's alpha was again used to examine the reliability of the proposed questions, using IBM SPSS Statistics v. 24, taking the general rule of thumb that values of 0.7 or higher would indicate an acceptable level of reliability (Santos, 1999). ANOVA was conducted on the data using the same software.

\section{Survey results}

\subsection{Descriptions}

The pre survey was administered to 26 students, from $11^{\text {th }}$ grade. Half of the respondents were female, and 21 students were 16 years-old (the other 5 were 17). As regards the first year college students, 18 students voluntarily responded to the survey (out of a class of 28). 5 were female, 12 were male and one preferred not to specify. All but one were 18 years old. The percentage of female students who took the survey in the undergraduate class was $29.4 \%$, in close agreement with the average percentage in Portuguese Engineering degrees $(26.6 \%$ in 2016 according to PORDATA database). The student who preferred not to specify his/her gender was included in all the constructs but the gender one.

\subsection{Reliability assessment}

Table 1 summarizes the results of the calculation of Cronbach's Alpha for each of the constructs. As this table indicates, the questions for the constructs C, I, G, U and PC had a Cronbach's alpha which was greater than 0.70 , and close to those in the original study by Hoegh and Moskal (2009). In the Professional construct, however, the alpha level was lower than for the other constructs, just above the accepted cut-off of 0.70 for the pre-university students and well below the cut-off for first year participants. This is in line with the results obtained by Heersink and Moskal (2010), who encountered similar problems.

Table 1. Cronbach's Alpha for each construct

\begin{tabular}{ccc}
\hline Construct & Pre-university students & First year college students \\
\hline Confidence (C) & 0.843 & 0.816 \\
Interest (I) & 0.940 & 0.931 \\
Gender (G) & $0.845^{*}$ & $0.823^{* *}$ \\
Usefulness (U) & 0.866 & 0.779 \\
Professional (P) & 0.711 & 0.459 \\
Peer-coaching (PC) & 0.882 & 0.765 \\
\hline
\end{tabular}

* One of the questions had zero variance and was removed from the scale.

${ }^{* *}$ Two questions had zero variance and were removed from the scale.

\subsection{Survey results}

The grand means and standard deviations for each of the constructs, both in the pre and in the post surveys, are summarized in Table 2 (without taking gender into consideration). Table 3 shows gender differences within the same age group, while Table 4 shows age differences (i.e., before $v s$. after taking the course) within the same gender group. 
Table 2. Grand means and standard deviations for the constructs. Statistically significant differences $(\mathrm{p}<0.05)$ are highlighted in bold.

\begin{tabular}{ccccc}
\hline \multirow{2}{*}{ Construct } & \multicolumn{2}{c}{ Pre-university students } & \multicolumn{2}{c}{ First year college students } \\
\cline { 2 - 5 } & Grand mean & SD & Grand mean & SD \\
\hline Confidence (C) & 2.94 & 0.35 & 3.18 & 0.42 \\
Interest (I) & $\mathbf{2 . 6 6}$ & 0.24 & $\mathbf{3 . 0 8}$ & 0.21 \\
Gender (G) & 3.84 & 0.15 & 3.85 & 0.17 \\
Usefulness (U) & $\mathbf{2 . 8 1}$ & 0.38 & $\mathbf{3 . 4 1}$ & 0.27 \\
Professional (P) & 3.40 & 0.21 & 3.50 & 0.42 \\
Peer-coaching (PC) & 2.88 & 0.11 & 2.72 & 0.29 \\
\hline
\end{tabular}

Table 3. Differences between genders within each age group. Statistically significant differences $(p<0.05)$ are highlighted in bold.

\begin{tabular}{cccccccccc}
\hline \multirow{2}{*}{ Construct } & \multicolumn{3}{c}{ Pre-university students } & \multicolumn{3}{c}{ First year college students } \\
\cline { 2 - 9 } & \multicolumn{2}{c}{ Male } & \multicolumn{3}{c}{ Female } & \multicolumn{3}{c}{ Male } & Female \\
\cline { 2 - 9 } & Grand mean & SD & Grand mean & SD & Grand mean & SD & Grand mean & SD \\
\hline Confidence (C) & 3.18 & 0.29 & 2.82 & 0.48 & 3.18 & 0.43 & 3.20 & 0.41 \\
Interest (I) & $\mathbf{3 . 0 0}$ & 0.25 & $\mathbf{2 . 3 7}$ & 0.30 & 3.08 & 0.20 & 3.06 & 0.33 \\
Gender (G) & 3.88 & 0.15 & 3.84 & 0.12 & $\mathbf{3 . 8 2}$ & 0.18 & $\mathbf{3 . 9 6}$ & 0.13 \\
Usefulness (U) & 2.98 & 0.25 & 2.65 & 0.53 & 3.42 & 0.29 & 3.40 & 0.24 \\
Professional (P) & 3.21 & 0.39 & 3.31 & 0.40 & 3.50 & 0.33 & 3.40 & 0.72 \\
Peer-coaching (PC) & $\mathbf{2 . 9 8}$ & 0.12 & $\mathbf{2 . 7 7}$ & 0.16 & 2.65 & 0.41 & 2.88 & 0.11 \\
\hline
\end{tabular}

Table 4. Differences same gender between different age groups. Statistically significant differences $(\mathrm{p}<0.05)$ are highlighted in bold.

\begin{tabular}{cccccccccc}
\hline \multirow{2}{*}{ Construct } & \multicolumn{3}{c}{ Male students } & \multicolumn{4}{c}{ Female students } \\
\cline { 2 - 8 } & \multicolumn{2}{c}{ Pre-university } & \multicolumn{2}{c}{ First year } & \multicolumn{3}{c}{ Pre-university } & First year \\
\cline { 2 - 8 } & Grand mean & SD & Grand mean & SD & Grand mean & SD & Grand mean & SD \\
\hline Confidence (C) & 3.18 & 0.29 & 3.18 & 0.43 & 2.82 & 0.48 & 3.20 & 0.41 \\
Interest (I) & 3.00 & 0.25 & 3.08 & 0.20 & $\mathbf{2 . 3 7}$ & 0.30 & $\mathbf{3 . 0 6}$ & 0.33 \\
Gender (G) & 3.88 & 0.15 & 3.82 & 0.18 & $\mathbf{3 . 8 4}$ & 0.12 & $\mathbf{3 . 9 6}$ & 0.13 \\
Usefulness (U) & $\mathbf{2 . 9 8}$ & 0.25 & $\mathbf{3 . 4 2}$ & 0.29 & $\mathbf{2 . 6 5}$ & 0.53 & $\mathbf{3 . 4 0}$ & 0.24 \\
Professional (P) & 3.21 & 0.39 & 3.50 & 0.33 & 3.31 & 0.40 & 3.40 & 0.72 \\
Peer-coaching (PC) & 2.98 & 0.12 & 2.65 & 0.41 & 2.77 & 0.16 & 2.88 & 0.11 \\
\hline
\end{tabular}

\subsection{Post-course students' feedback}

With regard to the post survey question on whether they would recommend the course to their friends, 15 out of the 18 participants said that they would ( 2 said that they would not and one did not answer). However, all agreed that the course should be offered on the next academic year.

In relation to the brief comments that the students wrote at the end of the survey, the majority of the participants stated that they had kept their original opinion about programming, regardless of whether it was positive or negative.

As regards peer-coaching, they generally agreed that it had been a rewarding experience and that the peer assisted approach had granted them more freedom, had resulted in a more relaxed atmosphere and had led to a closer interaction between the tutor and the tutees (due to the smaller age difference), which would in turn promote learning. However, several students also emphasized that they believed that Professors' experience could have improved general performance and led to more efficient time management (even if just by being present in the classroom while it was taught by the peer tutor). For example, one student indicated that (tr.) "Concerning classes given by students instead of teacher, I think it is a very good idea, because sometimes a better bond is created if the teacher is as young as us. I enjoyed it very much.", while another stated that (tr.) "I still consider programming somewhat confusing and not very appealing, but I am open to learning". 


\section{Discussion}

Overall there was an increase in the Likert scale for all constructs (see Table 2) after this introductory course to programming using Arduino, except for the peer-coaching one. In this latter group of questions, younger students seemed to be more eager to be taught in a less formal way and appeared to be more enthusiastic about the peer-assisted learning approach. Further, significant gender-related differences were found for pre-university students $(p=0.05)$, with male tutees being more prone to the PAL approach than their female classmates.

Concerning the confidence construct, there were no statistically significant differences between genders or ages, with high values for all populations. However, males tended to be more confident than females in the youngest group $(\mathrm{p}=0.0844)$, and females increased their confidence after taking the course $(\mathrm{p}=0.1080)$.

In relation to the interest construct, there were significant differences $(\mathrm{p}=0.0006)$ between the pre-university and the first year college participants: the latter expressed more interest. When replies to the survey were broken down by gender (see Table 3), statistically significant differences were found between pre-university males and females $(\mathrm{p}=0.0001)$ and between females before and after the course $(p=0.0001)$ : while amongst the younger tutees males were clearly more interested in programming than their female counterparts, elder students showed similar interest levels irrespective of their gender.

As regards the gender construct, it can be deemed as particularly important because, as noted above, women are one subpopulation that is severely underrepresented in undergraduate computer science majors (the failure of computer-related disciplines to appeal to women has been an abiding problem) (DuBow, et al., 2016), and remarkable gender related differences amongst computer science students have been reported (Putnik, Štajner-Papuga, Ivanović, Budimac, \& Zdravkova, 2017). From the surveys, a change in attitude seems to be underway: both populations agreed that women are as capable as men to excel in programming courses and careers that involve programming. In fact, it was the only construct in which all participants totally agreed in some questions (G10 for the pre survey and G1 and G13 for the post survey). The positive opinion was particularly high for female first year college students (significantly different from those of their younger counterparts, $\mathrm{p}=0.0408)$. Quasi-significant differences were found between male and female populations in the elder group $(\mathrm{p}=0.0534)$, with higher values for women.

In relation to the usefulness construct, older students seemed to be much more aware of the extent to which programming is useful to their own lives, even if they did not intend a computer science-related career $(\mathrm{p}=0.02)$. This could be biased by the fact that the chosen sample of students were already pursuing a STEM degree, but both pre-university and first year college participants recognized (questions U2 and U6) that knowledge of programming will allow them to secure a good job. Significant differences were also found, both for males and females, between preuniversity and first year college students ( $\mathrm{p}=0.04$ and $\mathrm{p}=0.02$, respectively).

In connection with the professional construct, albeit less reliable according to Cronbach's Alpha test, most answers seemed to point towards a good social acceptance of people who are skilled at programming, far from the 'nerd' stereotype.

With reference to the actual course, the degree of satisfaction was high and both younger and older tutees were engaged in learning and motivated to increase the complexity of the project step by step. The feeling of achievement after completing a project reinforced student motivation to pursue a STEM education. As an example, one of the students (L.S.) that participated in a previous edition of the jeKnowledge academy pre-university course, who has now taken a STEM-oriented itinerary at High School, explained that after pursuing the course he had chosen the topic of technology to make a presentation in his Portuguese language class. He presented some of the setups developed in the course and a video in front of his peers, claiming that (tr.) it had been a turning point for him, because from that point onwards he was able to understand how devices 
work, because he had been able to see how an instruction given to a computer was actually converted into an action.

\section{Conclusions}

In this paper a peer-to-peer coaching scheme for conducting an introductory programming course based on the Arduino open source platform was presented. Details of the different miniprojects chosen for the practical section of the 8 -hour course were provided, showing how they build to the acquisition of the basic computational thinking skills, keeping the tutees engaged in learning and motivated to increase the complexity step by step. The pre and post surveys indicated an overall increase in the Likert scale for all the programming-related constructs after the introductory Arduino course: high confidence values were obtained for all populations in terms of their own ability to learn computing skills; there was an increase in their interest in computing; they entirely agreed that women are as capable as men to excel in programming courses and careers that involve programming; they increased their awareness of the usefulness of learning computing, associating it to higher chances of getting a good job; and a good social acceptance of people who are skilled at programming, far from the 'nerd' stereotype, was reflected. On the other hand, in connection to the peer-assisted learning approach, younger tutees seemed to be more eager to be taught in a less formal way and appeared to be more enthusiastic about it than their older counterparts. Significant gender-related differences for pre-university students, with male tutees being more prone to the PAL approach than their female classmates, were also found. The general feedback provided by the participants was positive, with unanimous agreement on the convenience of continuing with these activities and approach in future editions.

Plans are currently underway for the next edition of the Arduino seminar for high school students. Adding a challenge-type activity may be conducted, in which the students participating in the Summer School would work in teams to develop a certain project over a period one/two weeks. This challenge would not only work as an advertisement vehicle for the Summer School, but would also provide the students with a more meaningful learning experience, but would also give them a better idea of what they will face in college course if they decide to pursue a computer science, a computer engineering or an electronics degree. As concerns the undergraduate students, extending it to other Portuguese and Spanish universities, involving members of robotics clubs that can act as tutors, is envisaged, with a view to retrieving data on a larger population sample.

\section{Funding sources}

This work was supported by FCT Portugal (reference UID/FIS/04564/2016); and Santander Universidades ("Becas Iberoamérica Jóvenes Profesores e Investigadores, España” program).

\section{References}

adafruit. (2015). Arduino Lesson 3. RGB LEDs. Available at: https://learn.adafruit.com/adafruitarduino-lesson-3-rgb-leds/arduino-sketch.

Aldridge, R., Brandt, T., \& Parikh, C. (2016). Autonomous Robot Design and Build: Novel Hands-on Experience for Undergraduate Students. In Proceedings of the 2016 ASEE North Central Section Conference (pp. 1-9). Mt Pleasant, MI, USA: American Society for Engineering Education.

AllAboutCircuits. (2015). An Arduino-Controlled Light Sensor project. Available at: http://www.allaboutcircuits.com/projects/an-arduino-controlled-light-sensor/.

Arduino. (2014). Arduino Starter Kit - Video Tutorials by Massimo Banzi. Available at: https://www.youtube.com/playlist?list=PLT6rF I5kknPf2qlVFlvH47qHvqvzkknd.

Arduino. (2015a). Analog In, Out Serial tutorial. Available at: https://www.arduino.cc/en/Tutorial/AnalogInOutSerial.

Arduino. (2015b). Blink tutorial. Available at: https://www.arduino.cc/en/Tutorial/Blink. 
Arduino. (2015c). Button tutorial. Available at: https://www.arduino.cc/en/Tutorial/Button.

Arduino. (2016a). Arduino user projects. Available at:

http://playground.arduino.cc/Projects/ArduinoUsers.

Arduino. (2016b). Project Ideas. Available at: http://playground.arduino.cc/Projects/Ideas.

Assaf, D. (2014). Enabling Rapid Prototyping in K-12 Engineering Education with BotSpeak, a Universal Robotics Programming Language. In Proceedings of 4th International Workshop Teaching Robotics, Teaching with Robotics \& 5th International Conference Robotics in Education (pp. 19-26). Padova, Italy: University of Padova.

Banzi, M., \& Shiloh, M. (2015). Getting started with Arduino (Third edition. ed.). Sebastopol, CA, USA: Maker Media Inc.

Barr, V., \& Stephenson, C. (2011). Bringing computational thinking to K-12. ACM Inroads, 2(1), 48.

Benitti, F.B.V. (2012). Exploring the educational potential of robotics in schools: A systematic review. Computers \& Education, 58(3), 978-988.

Capstick, S., \& Fleming, H. (2001). Peer assisted learning in an undergraduate hospitality course: second year students supporting first year students in group learning. Journal of Hospitality, Leisure, Sport \& Tourism Education, 1(1), 69-75.

Castillo-Manzano, J.I., Castro-Nuño, M., López-Valpuesta, L., Sanz-Díaz, M.T., \& Yñiguez, R. (2017). To take or not to take the laptop or tablet to classes, that is the question. Computers in Human Behavior, 68, 326-333.

Craft, B. (2013). Arduino Projects for Dummies. Chichester, West Sussex, UK: John Wiley \& Sons, Ltd.

Chou, P.-N., Chang, C.-C., \& Lin, C.-H. (2017). BYOD or not: A comparison of two assessment strategies for student learning. Computers in Human Behavior, 74, 63-71.

DuBow, W.M., Quinn, B.A., Townsend, G.C., Robinson, R., \& Barr, V. (2016). Efforts to Make Computer Science More Inclusive of Women. ACM Inroads, 7(4), 74-80.

Duncan, C., \& Bell, T. (2015). A Pilot Computer Science and Programming Course for Primary School Students. In WiPSCE'15 Proceedings of the Workshop in Primary and Secondary Computing Education (pp. 39-48). London, UK: ACM.

Eguchi, A. (2014). Robotics as a learning tool for educational transformation. In Proceeding of 4th International Workshop Teaching Robotics, Teaching with Robotics \& 5th International Conference Robotics in Education (pp. 27-34). Padova, Italy: University of Padova.

Emurian, H.H., Holden, H.K., \& Abarbanel, R.A. (2008). Managing programmed instruction and collaborative peer tutoring in the classroom: Applications in teaching Java ${ }^{\mathrm{TM}}$. Computers in Human Behavior, 24(2), 576-614.

Faludi, R. (2010). Building wireless sensor networks: with ZigBee, XBee, arduino, and processing. Sebastopol, CA, USA: O'Reilly Media, Inc.

García-Peñalvo, F.J. (2016). A brief introduction to TACCLE 3 -coding European project. In F.J. García-Peñalvo \& J.A. Mendes (Eds.), 2016 International Symposium onComputers in Education (SIIE) (pp. 1-4). Salamanca, Spain: IEEE.

Grover, S., \& Pea, R. (2013). Computational Thinking in K-12: A Review of the State of the Field. Educational Researcher, 42(1), 38-43.

Hacktronics. (2014). Arduino and 7 Segment LED tutorial. Available at: https://www.hacktronics.com/Tutorials/arduino-and-7-segment-led.html.

Heersink, D., \& Moskal, B.M. (2010). Measuring high school students' attitudes toward computing. In Proceedings of the 41st ACM technical symposium on Computer science education (pp. 446-450). Milwaukee, Wisconsin, USA: ACM.

Hoegh, A., \& Moskal, B.M. (2009). Examining science and engineering students' attitudes toward computer science. In Proceedings of the 39th IEEE international conference on Frontiers in education conference (pp. 1306-1311). San Antonio, Texas, USA: IEEE Press.

Instructables. (2016). 20 Unbelievable Arduino Projects. Available at: http://www.instructables.com/id/20-Unbelievable-Arduino-Projects/.

Jang, Y., Lee, W., \& Kim, J. (2015). Assessing the usefulness of object-based programming education using arduino. Indian Journal of Science and Technology, 8(S1), 89-96. 
Javed, A. (2016). Building Arduino Projects for the Internet of Things: Experiments with RealWorld Applications. New York City, NY, USA: Apress Media LLC.

jeKnowledge. (2016). jeKnowledge academy. Available at: http://jeknowledge.github.io/academy-articles/.

Junior, L.A., Neto, O.T., Hernandez, M.F., Martins, P.S., Roger, L.L., \& Guerra, F.A. (2013). A low-cost and simple arduino-based educational robotics kit. Cyber Journals: Multidisciplinary Journals in Science and Technology, Journal of Selected Areas in Robotics and Control (JSRC), December edition, 3(12), 1-7.

Kafai, Y.B., Lee, E., Searle, K., Fields, D., Kaplan, E., \& Lui, D. (2014). A crafts-oriented approach to computing in high school: Introducing computational concepts, practices, and perspectives with electronic textiles. ACM Transactions on Computing Education (TOCE), 14(1), 1-20.

Kafai, Y.B., Searle, K., Kaplan, E., Fields, D., Lee, E., \& Lui, D. (2013). Cupcake cushions, scooby doo shirts, and soft boomboxes: e-textiles in high school to promote computational concepts, practices, and perceptions. In SIGCSE'13: Proceeding of the 44th ACM technical symposium on Computer science education (pp. 311-316). Denver, Colorado, USA: ACM.

Kaye, L.K., \& Pennington, C.R. (2016). "Girls can't play": The effects of stereotype threat on females' gaming performance. Computers in Human Behavior, 59, 202-209.

Lessner, D. (2014). Analysis of Term Meaning "Computational Thinking". Journal of Technology and Information, 6(1), 71-88.

Lundeberg, M.A., \& Moch, S.D. (1995). Influence of Social Interaction on Cognition: Connected Learning in Science. The Journal of Higher Education, 66(3), 312.

Lye, S.Y., \& Koh, J.H.L. (2014). Review on teaching and learning of computational thinking through programming: What is next for K-12? Computers in Human Behavior, 41, 5161.

MakeUseOf. (2015). 10 Great Arduino Projects for Beginners. Available at: http://www.makeuseof.com/tag/10-great-arduino-projects-for-beginners/.

McRoberts, M. (2010). Beginning Arduino. New York, NY, USA: Apress Media LLC.

Merkouris, A., \& Chorianopoulos, K. (2015). Introducing Computer Programming to Children through Robotic and Wearable Devices. In WiPSCE'15: Proceedings of the Workshop in Primary and Secondary Computing Education (pp. 69-72). London, UK: ACM.

Mondragon, A.F., \& Becker-Gomez, A. (2012). So many educational microcontroller platforms, so little time! In 2012 American Society for Engineering Education Annual Conference and Exposition (pp. 1-16). San Antonio, Texas, USA: American Society for Engineering Education.

Monk, S. (2010). 30 Arduino projects for the evil genius. New York, NY, USA: McGraw-Hill.

Nussey, J. (2013). Arduino for Dummies. Chichester, West Sussex, UK: John Wiley \& Sons, Ltd.

Putnik, Z., Štajner-Papuga, I., Ivanović, M., Budimac, Z., \& Zdravkova, K. (2017). Gender related correlations of computer science students. Computers in Human Behavior, 69, 91-97.

Reas, C., \& Fry, B. (2014). Processing: a programming handbook for visual designers and artists (2nd Ed). Cambridge, MA, USA: MIT Press.

Rees, A., García-Peñalvo, F.J., Jormanainen, I., Tuul, M., \& Reimann, D. (2016). An overview of the most relevant literature on coding and computational thinking with emphasis on the relevant issues for teachers. Belgium: TACCLE3 Consortium.

Rubio, M.A., Hierro, C.M., \& Pablo, A. (2013). Using Arduino to enhance Computer Programming courses in Science and Engineering. In Proceedings of EDULEARN13 Conference (pp. 978-984). Barcelona, Spain: IATED.

Santos, J.R.A. (1999). Cronbach's alpha: A tool for assessing the reliability of scales. Journal of extension, 37(2), 1-5.

Serrano-Cámara, L.M., Paredes-Velasco, M., Alcover, C.-M., \& Velazquez-Iturbide, J.Á. (2014). An evaluation of students' motivation in computer-supported collaborative learning of programming concepts. Computers in Human Behavior, 31, 499-508. 
Smith, J., May, S., \& Burke, L. (2007). Peer Assisted Learning: a case study into the value to student mentors and mentees. Practice and Evidence of the Scholarship of Teaching and Learning in Higher Education, 2(2), 80-109. 


\section{First exposure to Arduino through peer-coaching: impact on students' attitudes towards programming}

\section{Highlights}

- Student-led introductory programming course for high-school students using Arduino

- Project-based approach for acquisition of computational thinking skills via PAL

- Pre and post surveys showed overall increase for all programming-related constructs

- Students totally agreed that women are as capable as men to excel in programming

- Significant age- and gender-related differences in attitude towards PAL were found 